\title{
The Impact of Youth's Biospheric Interests on their Awareness and Expectations about Nuclear Power Technology in the United Arab Emirates
}

\author{
Ibrahim Niankara \\ College of Business, Al Ain University of Science and Technology, P.O. Box: 112612, Abu Dhabi, UAE; Tel: \\ +97124444696 Ext: 539 ; Fax: +97124444304; E-mail: ibrahim.niankara@aau.ac.ae
}

\begin{abstract}
Relying on the United Arab Emirates (UAE) extract from the cross-national data sample on the environmental affection and cognition of adolescent students, and seemingly unrelated bivariate weighted ordered probit regression modeling, this study adopts a national perspective to investigate the determinants of adolescent students' awareness and expectations about nuclear power technology and nuclear waste in the UAE. Identification of model parameters is achieved through maximum simulated likelihood estimation. The findings show that each level increase in UAE youth's interest in ecosystem services and sustainability raises their awareness of nuclear electrical power and nuclear waste by $13.5 \%$, while reducing by $2.4 \%$ their level of optimism towards the technology. Furthermore, we find significant heterogeneity in youth awareness and expectations about nuclear power technology across the seven Emirates. Accounting for all other factors (including interest in ecosystem services), UAE youth awareness about nuclear electrical power technology appears to not significantly influence their expectations about the evolution of this technology for the next 20 years. Given that the UAE first nuclear power plant "Barakah" is scheduled to start operations end of 2019 beginning 2020, and the typical long life-span of nuclear wastes, our results provide important insights for developing sustainable nuclear energy policies and establishing a long-term nuclear energy program in the UAE.
\end{abstract}

Keywords: Clean Energy Production, Nuclear Awareness, Nuclear Electrical Power, Nuclear Optimism, Nuclear Waste, Sustainable Development

JEL: D83, D84, P48, Q01, Q5, Q57 


\section{Introduction}

"Adolescence is a critical life stage during which individuals must have the opportunity to develop the capabilities required for realizing their full potential...transitions from adolescence to adulthood require investments in information... and opportunities to participate in decision-making...such investments will benefit not only young people who need them, but also their communities and countries" Ki-moon, 2016).

Some of the key preconditions for adolescents full participation in modern societies include their degree of preparedness, and resulting awareness and expectations about the pressing issues in contemporary societies, including that of using technology to meet the demands of everyday living (Yoshida, 2015). With the Earth's population currently growing at an unprecedented rate(Coccia, 2014), one of the pressing challenges that the youth of today will have to address in the near future is the question of energy security, and its relationship with green house gas emission and global warming (Ozcan and Ari, 2017). In the United States for example, drawing from the literature on the Theory of Planned Behavior (TPB) and community resilience, Craig and Sayers (2019) shows how awareness of local clean energy initiatives, risk perceptions, environmental messaging, and environmental orientation influence young millennial support for federal clean energy policy and taxes.

In the United Arab Emirates (UAE), population and economic growth have created a sharp increase in energy demand in the last decade (Shahbaz et al., 2014; Pioro and Duffey, 2019). Between 2000 and 2013 electricity production increased more than 13.5\%, from 39.9 TWh to 110 TWh for an average annual increase of $5.39 \mathrm{TWh}$, while electric power consumption during the same period, rose by $13.3 \%$ annually, at an average of 5.14 TWh(Juaidi et al., 2016). Per capita electricity consumption is an indicator that places the UAE among the highest energy consumers in the world, at the 10th position in 2012 with $10.13 \mathrm{MWh}$ per capita consumption (Pioro and Duffey, 2019). With respect to per capita carbon dioxide (CO2) emissions, the UAE has dropped from 2nd position of worldwide top polluters in the period 2000-2004 to 8th in 2010, and back again to 2nd position in 2013 (Juaidi et al., 2016).

As a result, the UAE has recently announced a 2050 Energy Plan that aims for a $50 \%$ clean energy supply (Lim et al. 2018). The plan requires the nation to diversify its energy mix and adopt more renewable energy sources (Sgouridis et al., 2013, 2016). Nuclear power energy has also been viewed as a controversial yet viable energy option for reducing carbon emissions, alleviating global warming and transitioning to low-carbon societies(Jacobson, 2009; Ahearne, 2011; Gattie et al., 2018; Uddin, 2019). Several authors investigated its potential to mitigate CO2 emissions (Barron and Hill, 2019; Sornette et al., 2019) including in the United Arab Emirates (AlFarra and AbuHijleh, 2012). For example, applying Life Cycle Assessment (LCA)(Turconi et al., 2013) to a variety of scenarios for future power generation in the UAE, Treyer and Bauer (2016) reports that nuclear power shows positive environmental effects in most impact categories; though many technical, 
economic and social hurdles remain to be cleared for nuclear power to effectively contribute to the national electricity supply (Budnitz et al., 2018).

Indeed, in evaluating overnight construction costs (OCC) and lead-time escalation of nuclear power construction projects from 1955 to 2016, Portugal-Pereira et al. $(\overline{2018})$ reveal a significant delay in lead-time, resulting in capital costs escalation rather than decline. The authors recommended that the role of nuclear technology as an alternative to cope with the need for power sector decarbonisation be better evaluated, taking into account the real cost impacts of nuclear technology implementation. Similarly, focusing on the cost feasibility of nuclear waste management, (Barron and Hill, 2019) reports nuclear energy's economic attractiveness as a low carbon energy option to be lower than earlier works suggested, especially when more realistic nuclear waste management cost models and uncertainty-appropriate inter-generational discount rates are considered.

In addition to prohibitive overnight construction and waste management costs, the general public often associates nuclear energy with risks that include nuclear accidents, nuclear waste contamination, nuclear weapons proliferation, among others (Yoshida, 2015; Wheatley et al., 2016; Ho et al., 2019). The 1979 three mile Island incident in Pennsylvania, the 1986 Chernobyl nuclear disaster in Ukraine, and the more recent 2011 Fukushima-Daichii nuclear accident (Van Ness and Gurtov, 2017) have all contributed to the observed public dissent for nuclear energy technology over the past few decades (Fan, 2018). Overall however, public perception of nuclear energy is shaped by a host of other factors including trust in nuclear governing institutions (Sovacool and Valentine, 2012), knowledge (Ho et al., 2019), political inclinations (Richter, 2017), geographical proximity, and socio-demographic factors (Harris et al., 2018).

Given the general divisions in the use of nuclear power technology (Chien, 2014; Cottrell, 2017), understanding public and specifically youth's awareness and optimism about nuclear technology, and identifying the determinants of acceptance are vital to making national nuclear energy policies and establishing long-term nuclear energy programs (Arikawa et al., 2014; Stefanelli et al., 2017; Edwards et al., 2019). The present study therefore, as a follow up to Niankara (2018) and Niankara and Zoungrana (2018) inscribes itself in this dynamic, using the cross-national data sample on the environmental affection and cognition of adolescent students (Niankara, 2019). It focuses specifically on nuclear electrical power technology and nuclear waste awareness and expectations, in the country with the world largest nuclear power project under construction, namely the UAE (Lim et al., 2018). The general question the study seeks to address is:

How does interest in ecosystem services and sustainability affect youth nuclear electrical power technology and nuclear waste awareness and expectation in the United Arab Emirates?

Despite the importance of ecosystem services and sustainability in regional planning and development (Tammi et al., 2017), and the strategic position of nuclear electrical power in the UAE energy mix (AlFarra and Abu-Hijleh, 2012; Treyer and Bauer, 2016), only one study to the best of our knowledge reports on public acceptance of nuclear energy in the country (World Nuclear 
News, 2017). No prior study in the scientific discourse addresses public awareness and optimism about the use of nuclear technology in the UAE. Given its current infancy in the country (Nagraj, 2018), and the long life-span of nuclear wastes (Lenzen, 2008), present day UAE adolescents would inevitably be the adults decision makers in charge of dealing with the first waves of nuclear wastes produced by the UAE "Barakah" nuclear power plant. It is therefore imperative to get a clear picture of current UAE adolescent population's awareness and optimism about nuclear technology in general, and nuclear waste in particular so as to properly plan for the optimal and sustainable use of the technology in the country. To this end, the rest of the paper is organized as follows; section 2 provides a background discussion on nuclear electrical power in the UAE; section 3 presents the methods used to answer the question, by first describing the data, followed by the variables used in the analysis, and ending with the econometric model; section 4 presents the results, while section 5 discusses the policy implications and concludes the analysis.

\section{Background on Nuclear Electrical Power in the United Arab Emirates}

The United Arab Emirates (UAE) was founded in 1971 by the union of seven states (Emirates) including Abu Dhabi, Dubai, Sharjah, Ajman, Umm Al Quwain, Ras Al Kaimah, and Fujairah. The emirate of Abu Dhabi, which accounts for $86 \%$ of the UAE land area and $95 \%$ of its oil, represents the federal capital of the country, while Dubai seats as the UAE's largest city (Zahlan, 2016). In 2015 the UAE produced 127 TWh of electricity, all from fossil fuels - 125.5 TWh natural gas, and 1.5 TWh oil (World Nuclear Association, 2018). Electricity demand has been on the rise and the country relies entirely on electricity to provide its potable water, by desalination(Saif and Almansoori, 2016).

In April 2008 the UAE independently published a comprehensive policy on energy that projected escalating electricity demand from 15.5 GWe in 2008 to over 40 GWe in 2020 (Sim, 2012). Natural gas was set to account for half of this needed power, renewable for about 6-7\% (Eveloy and Gebreegziabher, 2019), while coal was dismissed as an option due to environmental and energy security implications(Khondaker et al., 2016). Nuclear power emerged as a proven, environmentally promising and commercially competitive option which could make a significant contribution to the UAE's economy and future energy security (AlFarra and Abu-Hijleh, 2012). This led to the creation of a regulatory framework and selection of a site between Abu Dhabi city and Ruwais, at Barakah (see figure 1).

\subsection{The UAE nuclear electrical power program}

Following the creation of its regulatory framework, and as recommended by the international atomic energy agency (IAEA), the UAE established a Nuclear Energy Program Implementation Organization, which set up the Emirates Nuclear Energy Corporation (ENEC) as an Abu Dhabi public entity, initially funded with $\$ 100$ million, to evaluate and implement nuclear power plans 
within UAE (World Nuclear Association, 2018). In December 2009 ENEC selected a bid from the Korea Electric Power Corporation(KEPCO)-led consortium to build four APR1400 reactors. The value of the contract for the construction, commissioning, and fuel loads for four units was about $\$ 20.4$ billion, with a high percentage of the contract being offered under a fixed-price arrangement (Park and Chevalier, 2010). The consortium also expects to earn another $\$ 20$ billion by jointly operating the reactors for 60 years. In March 2010 KEPCO awarded a $\$ 5.59$ billion construction contract to Hyundai and Samsung for the first plants at the "Barakah cite".

\subsection{The "Barakah" nuclear power plant}

As the world largest nuclear power plant under construction, at a cost of $\$ 32 \mathrm{bn}$ and a total capacity of 5,600MW distributed across four units of 1,400MW each, the "Barakah" plant is the first nuclear power project being developed in the UAE (World Nuclear Association, 2018). Construction of the first unit started in July 2012 by Emirates Nuclear Energy Corporation (ENEC), approximately $53 \mathrm{~km}$ west-southwest of the city of Ruwais (see figure 1), following receipt of construction license from the Federal Authority of Nuclear Regulation (FANR) and environmental approval from the Environment Agency - Abu Dhabi]. The plant was due to start operation in 2017, but has been delayed until the end of 2019 beginning 2020 (Langton, 2018; Reuters, 2018; Nagraj, 2018).

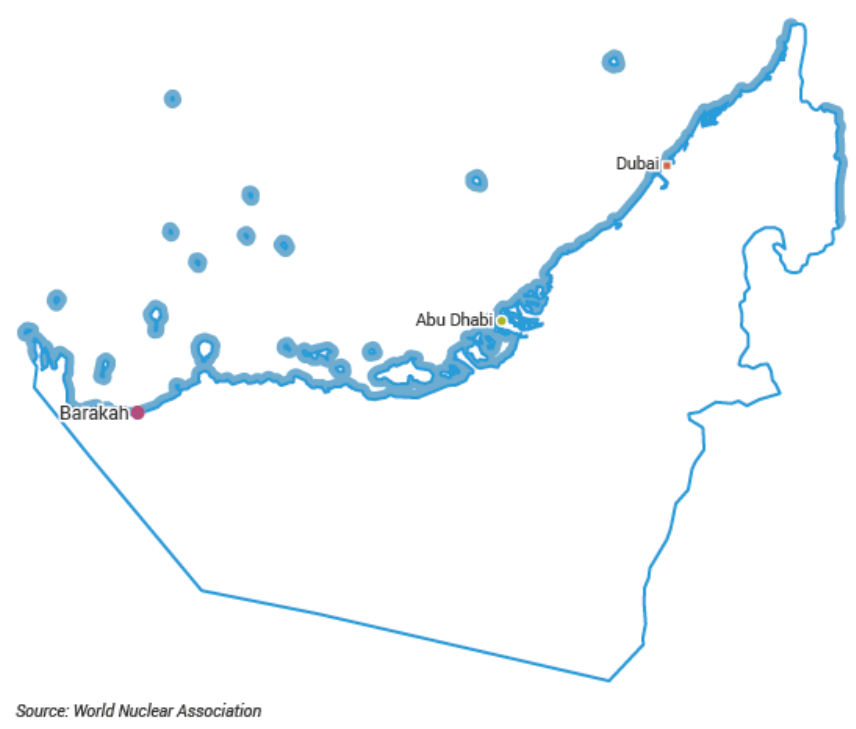

Figure 1: Nuclear Power Plant in the United Arab Emirates

\footnotetext{
${ }^{1}$ For more information visit https://www.power-technology.com/projects/barakah-nuclear-power-plant-abudhabi.
} 


\subsection{Fuel Cycle, and Nuclear Waste}

Nuclear reactors are typically loaded with Uranium Oxide fuel, $\mathrm{UO}_{2}$ (Schmidt and Jurado, 2018). Neutrons are introduced to the system, and many of them are absorbed by uranium atoms, causing them to become unstable and split, or fission, into two smaller atoms known as fission products as described in figure 2. Nuclear waste, with regard to nuclear reactors, is the collection of nuclides left over after a reactor has extracted some energy out of the nuclear fuel (Knapp and Pevec, 2018). Many of the resulting isotopes are very radioactive causing the spent nuclear fuel to continue emitting heat long after it has been removed from the reactor (Lenzen, 2008). In practice, the spent fuel is never unshielded, but kept underwater for a few years until the radiation decays to levels that can be shielded by concrete in large storage casks.

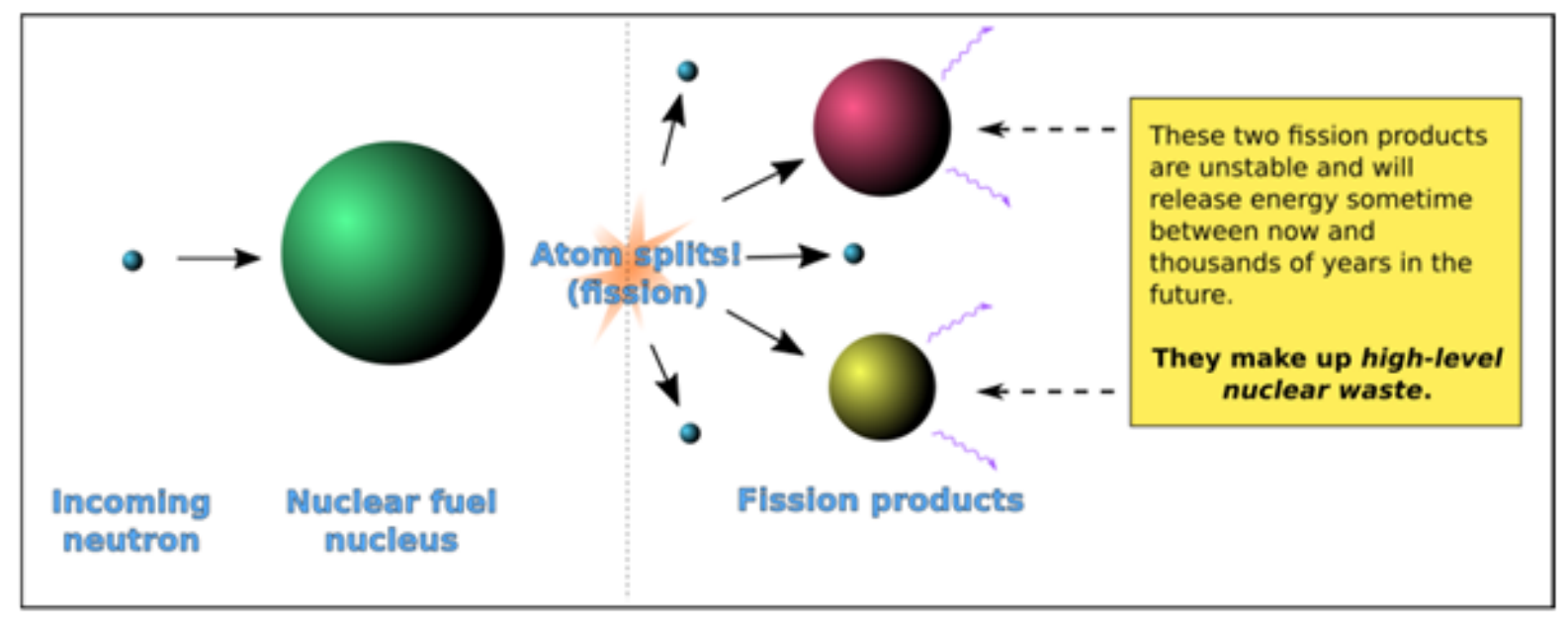

Figure 2: Single Atomic Fission process

According to the World Nuclear Association (2018), by August 2012 ENEC had awarded six contracts worth $\$ 3$ billion, and related to the supply of natural uranium concentrates, conversion and enrichment services individually, and the purchase of some enriched uranium product $t^{2}$. The UAE has also committed to a "dual track" radioactive waste management strategy that involves developing a national storage and disposal program in parallel with exploring regional cooperation options, which now appear more attractive with the Golf Countries Council (GCC) (Hvidt, 2017).

\footnotetext{
${ }^{2}$ The contracts involve Canada-based Uranium One, UK-based Rio Tinto, France's Areva, and Russia's Techsnabexport (Tenex) for supply of uranium concentrates. For conversion services, contracts utilize the USA's Converdyn, Tenex, and Areva. Enrichment will be by Europe-based Urenco, Areva, and Tenex. The enriched uranium will be supplied to Kepco Nuclear Fuels - part of the prime contractor consortium led by Korea Electric Power Corporation (Kepco) - which will manufacture the fuel assemblies.
} 
A further option is fuel take-back, returning it to suppliers. Used fuel will be stored in reactor ponds for up to 20 years, or may be transferred to dry storage after six years. Ownership and responsibility for the used fuel will be transferred to a new state-owned entity after about 20 years. Prospective studies of a geological waste repository in UAE, are also being undertaken by Sweden's SKB and the Arab Atomic Energy Agency (AAEA), with a widened group of participating Middle East and North African (MENA) countries for regional options along the lines of European Union precedents.

\section{Methods}

\subsection{Data and Variables Description}

The data used in this analysis comes from the "Cross-national Data Sample on the Environmental Affection and Cognition of Adolescent Students of Varying Interests in Ecosystem Services and Sustainability" (Niankara, 2019). This data contains information on 187821 students from 50 countries worldwide. After downloading the published data-set from "Data in Brief", we queried the UAE subset for the present analysis. For additional description on its sampling design see the OECD report( OECD, 2017, 67-91). The extracted UAE data for the present analysis contains information on 6919 students respondents, and is presented in table (2). The exposition in this section closely follow the methodology presented in Niankara and Zoungrana (2018).

\subsubsection{Dependents Variables}

The dependent variables in the present analysis are students' levels of awareness and expectations about the waste produced by the use of nuclear electrical power technology:

- SEANW: Self-Expressed-Awareness of Nuclear Waste (mean value $=2.62$, standard deviation $=0.98$ ): ordinal variable taking the values (1-Never heard, 2-Heard but can't explain, 3-Know and can provide general explanation 4-Familiar and can provide detail explanation).

- SEENW: Self-Expressed-Expectation of Nuclear Waste (mean value $=2.07$, standard deviation $=0.82$ ): also an ordinal variable taking the values (1-worse, 2-same, 3-Improve).

\subsection{Econometric Model Specification}

Following the seemingly unrelated bivariate weighted ordered probit model of awareness and expectation presented in Niankara (2018) and subsequently expended in Niankara and Zoungrana (2018), which is derived from the latent variable framework described in (Sajaia, 2008), we assume that the latent awareness $\left(A^{*}\right)$ and Expectation $\left(E^{*}\right)$ about nuclear electrical power technology, for student respondent's $i$ in region $j$ within the UAE are determined by the following two equations: 


$$
\begin{aligned}
& A_{i j}^{*}=\alpha_{1 j}+\mathbf{x}_{1 i}^{\prime} \beta_{1}+\epsilon_{1 i j} \\
& E_{j i}^{*}=\alpha_{2 j}+\mathbf{x}_{2 i}^{\prime} \beta_{2}+\gamma A_{i j}^{*}+\epsilon_{2 i j}
\end{aligned}
$$

Where $\beta_{1}$ and $\beta_{2}$ are unknown parameters to be estimated, $\gamma$ is an unknown scalar capturing the effect of students' awareness of nuclear electrical power technology on their expectations/optimism about the use of nuclear technology for electricity production in the UAE. $\epsilon_{1 i j}$ and $\epsilon_{2 i j}$ are the random disturbance terms for the latent awareness and expectations equations respectively. $\alpha_{1 j}$ and $\alpha_{2 j}$ denote the region specific effects in the awareness and expectation equations respectively. The predictor variables are assumed exogenous in the model system, such that $E\left(\mathbf{x}^{\prime}{ }_{1 i} \epsilon_{1 i j}\right)=$ $E\left(\mathbf{x}_{2 i}^{\prime} \epsilon_{2 i j}\right)=0$.

As presented in equation (1), the model system assumes the presence of unobserved heterogeneity in students' awareness $\left(A_{i j}^{*}\right)$ and expectations $\left(E_{i j}^{*}\right)$ across regions $j$ within the UAE, which are captured by the non-constant model intercepts $\alpha_{i j}$. These region-specific effects are the leftover sources of variation in adolescent students' awareness and expectations about nuclear electrical power technology that cannot be explained by their interest in ecosystem services and other included covariates in the model. They capture spatial variations in students nuclear power technology awareness and expectations, potentially linked to their locational proximity to the "Barakah" nuclear power plant. Since the plant is much closer to the Emirate of Abu Dhabi, the latter is chosen as the region of reference. Because of the potential correlation between these region-specific effects and the included explanatory variables (such as students' interest in ecosystem services and sustainability), the fixed effect estimator as implemented here using the Rchoice package(Sarrias, 2016) would be more appropriate for the identification of the model system.

Since the sample space covers all 7 regions (emirates) in the UAE, the above described approach implies that we would have 7-1 = 6 regional fixed effects, representing the average differences in students' levels of awareness and expectations about nuclear electrical power technology between students in the emirate of Abu Dhabi (the reference region), and those in the other remaining 6 emirates (regions) in the UAE. These regional fixed effects are recovered after estimation using the following equations:

$$
\begin{aligned}
& \hat{\alpha}_{1 j}=\bar{A}_{i j}^{*}-\overline{\mathbf{x}}_{i}^{\prime} \hat{\beta}_{1} \\
& \hat{\alpha}_{2 j}=\bar{E}_{i j}^{*}-\overline{\mathbf{x}}_{i}^{\prime} \hat{\beta}_{2}-\bar{A}_{i j}^{*} \hat{\gamma}
\end{aligned}
$$

Abstracting from the regional subscript $j$, the observed indicators of student's self-expressed awareness $(S E A N W)$ and self-expressed Expectations $(S A E N W)$ about nuclear electrical power technology in the UAE, are related to their corresponding latent variables in equation (1) as: 


$$
S E A N W_{i}= \begin{cases}1-\text { Never Heard } & \text { if } A_{i}^{*} \leq \mu_{1} \\ 2-\text { Heard, but Unable to Explain } & \text { if } \mu_{1} \leq A_{i}^{*} \leq \mu_{2} \\ 3-\text { Know, can provide General Explanation } & \text { if } \mu_{2} \leq A_{i}^{*} \leq \mu_{3} \\ 4-\text { Familiar, can provide Detailed Explanation } & \text { if } \mu_{3}<A_{i}^{*}\end{cases}
$$

$$
S A E N W_{i}= \begin{cases}1-\text { Worse } & \text { if } E_{i}^{*} \leq \delta_{1} \\ 2-\text { Same } & \text { if } \delta_{1} \leq E_{i}^{*} \leq \delta_{2} \\ 3-\text { Improve } & \text { if } \delta_{2}<E_{i}^{*}\end{cases}
$$

Where $\mu_{1}<\mu_{2}<\mu_{3}$ and $\delta_{1}<\delta_{2}$ are unknown cutoffs points. For identification purposes, following Jackman (2000); McKelvey and Zavoina (1975) we define $\mu_{1}=\delta_{1}=0$, while $\mu_{0}=\delta_{0}=$ $-\infty$ and $\mu_{4}=\delta_{3}=+\infty$ in order to avoid handling the boundary cases separately. For any two index $j$ and $k$ on the two latent scales, the probability that $S E A N W_{i}=j$ and $S A E N W_{i}=k$ is given by:

$$
\begin{aligned}
\operatorname{Pr}\left(S E A N W_{i}=j, S A E N W_{i}=k\right) & =\operatorname{Pr}\left(\mu_{j-1}<A_{i}^{*} \leq \mu_{j}, \delta_{k-1}<E_{i}^{*} \leq \delta_{k}\right) \\
& =\operatorname{Pr}\left(A_{i}^{*} \leq \mu_{j}, E_{i}^{*} \leq \delta_{k}\right) \\
& -\operatorname{Pr}\left(A_{i}^{*} \leq \mu_{j-1}, E_{i}^{*} \leq \delta_{k}\right) \\
& -\operatorname{Pr}\left(A_{i}^{*} \leq \mu_{j}, E_{i}^{*} \leq \delta_{k-1}\right) \\
& +\operatorname{Pr}\left(A_{i}^{*} \leq \mu_{j-1}, E_{i}^{*} \leq \delta_{k-1}\right)
\end{aligned}
$$

Assuming the joint distribution of $\epsilon_{1 i}$ and $\epsilon_{2 i}$ is bivariate standard normal, with correlation $\rho$ each student's contribution to the likelihood function is expressed as:

$$
\begin{aligned}
\operatorname{Pr}\left(S E A N W_{i}=j, S A E N W_{i}=k\right) & =\Phi_{2}\left(\mu_{j}-\alpha_{j}-\mathbf{x}_{1 i}^{\prime} \beta_{1},\left(\delta_{k}-\alpha_{k}-\gamma \mathbf{x}_{1 i}^{\prime} \beta_{1}-\mathbf{x}_{2 i}^{\prime} \beta_{2}\right) \zeta, \tilde{\rho}\right) \\
& -\Phi_{2}\left(\mu_{j-1}-\alpha_{j-1}-\mathbf{x}_{1 i}^{\prime} \beta_{1},\left(\delta_{k}-\alpha_{k}-\gamma \mathbf{x}_{1 i}^{\prime} \beta_{1}-\mathbf{x}_{2 i}{ }_{2 i} \beta_{2}\right) \zeta, \tilde{\rho}\right) \\
& -\Phi_{2}\left(\mu_{j}-\alpha_{j}-\mathbf{x}_{1 i}^{\prime} \beta_{1},\left(\delta_{k-1}-\alpha_{k-1}-\gamma \mathbf{x}_{1 i}^{\prime} \beta_{1}-\mathbf{x}_{2 i}{ }_{2 i}\right) \zeta, \tilde{\rho}\right) \\
& +\Phi_{2}\left(\mu_{j-1}-\alpha_{j-1}-\mathbf{x}_{1 i}^{\prime} \beta_{1},\left(\delta_{k-1}-\alpha_{k-1}-\gamma \mathbf{x}_{1 i}^{\prime} \beta_{1}-\mathbf{x}^{\prime}{ }_{2 i} \beta_{2}\right) \zeta, \tilde{\rho}\right)
\end{aligned}
$$

where $\zeta=\frac{1}{\sqrt{1+2 \gamma \rho+\gamma^{2}}}$ and $\tilde{\rho}=\zeta(\gamma+\rho)$. $\Phi_{2}$ is the cumulative distribution function of the bivariate standard normal. This specification is referred to as simultaneous bivariate ordered probit model. When $\rho=0$ the model simplifies to a seemingly unrelated specification with $\zeta=1$ and $\tilde{\rho}=\gamma$. As in Niankara (2018); Niankara and Zoungrana (2018) the model is estimated here under the weighted seemingly unrelated specification, using the package(Sarrias, 2016) from the $\mathrm{R}$ statistical software ( $\mathrm{R}$ Core Team, 2015). 


\section{Results}

\subsection{Descriptive Results}
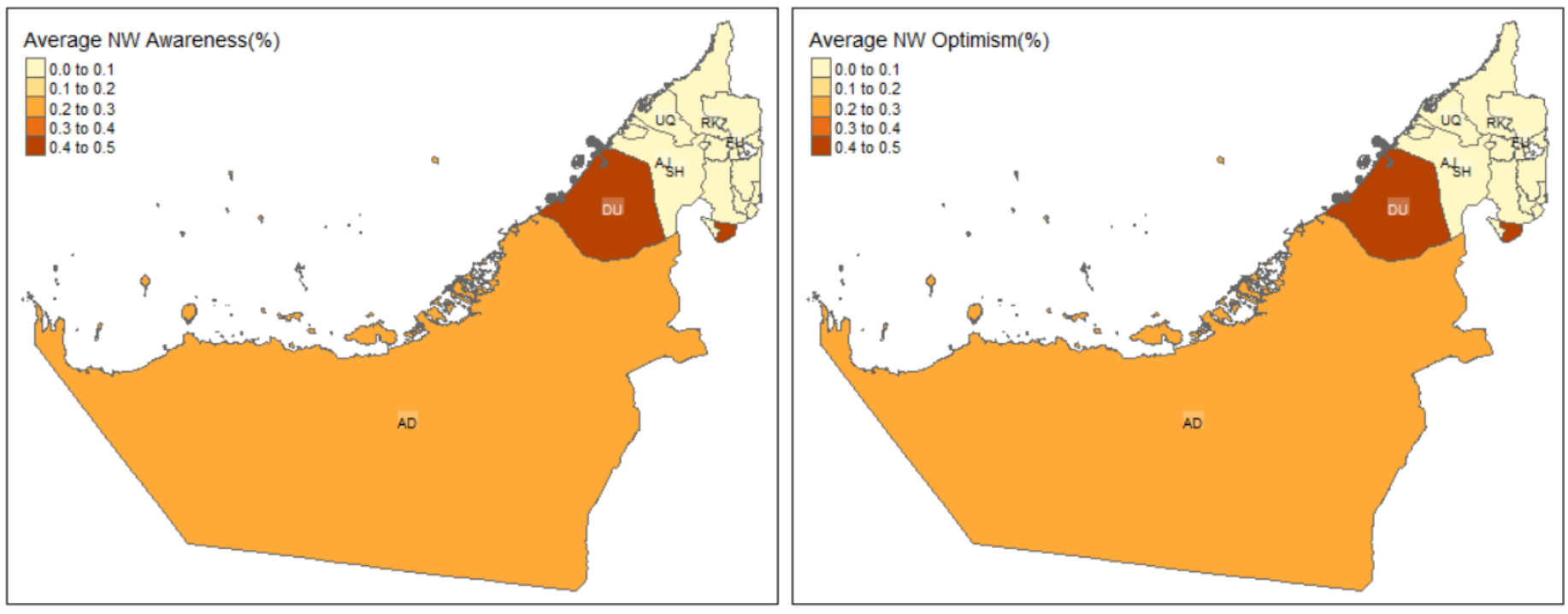

Figure 3: Distribution of Youth Nuclear Waste Awareness and Expectations across the seven Emirates

\subsubsection{Summary Statistics of the Explanatory Variables}

The summarized descriptive findings in table (2) show that overall, the greater majority of the adolescent respondents in our sample live in Dubai (47.98\%), followed by Abu Dhabi (23.65\%), then Sharjah (7.30\%), Ras Al Kaimah (6.65\%), Ajman (6.11\%), and finally fujairah $(6.01 \%)$. The average adolescent is somewhat interested (3.36) in ecosystem services and sustainability, but highly interested (3.99) in science as a means for diseases prevention. The standardized index of adolescent's enjoyment of science suggests that the average UAE student respondent is 0.59 standard deviation above the mean index value across all respondents in the 2015 Programme for International Student Assessment (PISA) (OECD, 2016). Furthermore, table (2) shows that the average UAE adolescent regularly visits ecological websites (3.02), and somewhat regularly news blogs (2.83). UAE adolescents also sometimes visit websites (2.65) and read books (2.93) on broad science.

The descriptive summary on the socio-economic and demographic factors show that $54.78 \%$ of UAE adolescent respondents are females, with an average age of 15.80 years. The mean value of the standard normalized scale of the index of economic, social and cultural status (ESCS) ${ }^{3}$, suggests

\footnotetext{
${ }^{3}$ Estimated across all OECD countries and partner countries on the basis of the following variables: the Interna-
} 
that the average UAE adolescent is 0.63 standard deviation above the mean index value across all respondents in the 2015 Programme for International Student Assessment (OECD, 2016). The distribution of respondents by immigration status suggests that $38.17 \%$ of the sample respondents are UAE natives, $38.76 \%$ are first generation expatriates, while the remaining $23.07 \%$ are second generation expatriates. With respect to grade level in school, table (2) shows that $0.36 \%$ of the adolescent respondents are 7 th graders, $1.29 \%$ are 8 th graders, $10 \%$ are 9 th graders, $55.73 \%$ are 10 th graders, $31.26 \%$ are 11 th graders, and finally $1.36 \%$ are 12 th graders or more.

\subsubsection{Nuclear Waste Awareness and Expectations Across levels of interest in Ecosystem Services}

The spatial distribution of youth Nuclear waste awareness and expectation across the seven emirates is presented in figure (3). Table (1) on the other hand summarizes the marginal relative frequency, and joint relative frequency distributions of youth's nuclear waste awareness (SEANW) and expectation (SEENW), with their levels of interest in ecosystem services and sustainability (IntBiosph) in the UAE.

With respect to the marginal relative frequencies of interest in ecosystem services and sustainability (IntBiosph), the last row of table (1) shows that the majority of UAE youth (38.69\%) report being interested in ecosystem services, followed by $24.27 \%$ that report being hardly interested, then by $19.57 \%$ that report not being interested, and $13.01 \%$ that report being highly interested, and finally $4.47 \%$ that report not knowing about it. Similarly, It can be noted from table (1) that the greatest share $(33.33 \%)$ of UAE youth report knowing about nuclear electrical power technology and nuclear waste, and able to provide general explanations; followed by $30.41 \%$ that report having heard about it, but unable to explain; then by $21.52 \%$ that report being familiar with it, and able to provide detailed explanations; and finally by $14.74 \%$ that report having never heard about it. With regards to respondents expectations about nuclear electrical power technology and nuclear waste in the next 20 years (SEENW), most UAE adolescent respondents (37.07\%) feel optimistic and believe it will improve, followed by $32.55 \%$ that believe it will remain the same, while the remaining $30.38 \%$ feel pessimistic, and believe it will get worse.

The joint relative frequency distribution, also in table (1) shows significant variations in percent relative cell frequencies as level of interest in ecosystem services and sustainability rises from 1don't know, to 5-highly interested, at every level of youth's nuclear waste awareness and expectation in the UAE. This latter finding is further confirmed by the chi-square test results shown in the last column of table (1). Indeed the p-values of the tests suggest highly significant $(\alpha=0.1 \%)$ relationships between youth's interest in ecosystem services and sustainability, and their self-

tional Socio-Economic Index of Occupational Status (ISEI); the highest level of education of the student's parents in years of schooling; the PISA index of family wealth; the PISA index of home educational resources; and the PISA index of possessions related to "classical" culture in the family home. See (OECD, 2017, pp. 339-340) for more details 
Table 1: Conditional and Relative Frequencies of Students' Nuclear Waste Awareness and Expectations

\begin{tabular}{|c|c|c|c|c|c|c|c|c|}
\hline & & \multicolumn{5}{|c|}{ IntBiosph } & \multirow{2}{*}{$\begin{array}{c}\text { Rel. Freq. } \\
(\%)\end{array}$} & \multirow[t]{2}{*}{$\mathrm{Chi}^{2}$ Stat. } \\
\hline & & 1 & 2 & 3 & 4 & 5 & & \\
\hline \multirow[t]{4}{*}{ SEANW } & 1 & 6.76 & 35.78 & 23.53 & 26.37 & 7.55 & 14.74 & $\mathrm{X}$-squared $=537.37^{* * *}$ \\
\hline & 2 & 4.52 & 22.67 & 27.95 & 36.74 & 8.13 & 30.41 & $\mathrm{df}=12, \mathrm{p}$-value $<2.2 \mathrm{e}-16$ \\
\hline & 3 & 4.16 & 14.44 & 24.63 & 44.15 & 12.62 & 33.33 & \\
\hline & 4 & 3.29 & 12.02 & 19.01 & 41.44 & 24.24 & 21.52 & - - - - - - - - - - - - \\
\hline \multirow[t]{3}{*}{ SEENW } & 1 & 4.52 & 17.84 & 23.36 & 40.06 & 14.22 & 30.38 & $\mathrm{X}$-squared $=20.74^{* *}$ \\
\hline & 2 & 4.17 & 19.63 & 25.75 & 39.21 & 11.23 & 32.55 & $\mathrm{df}=8, \mathrm{p}$-value $=0.00787$ \\
\hline & 3 & 4.68 & 20.94 & 23.70 & 37.12 & 13.57 & 37.07 & \\
\hline Rel. Freq. & $(\%)$ & 4.47 & 19.57 & 24.27 & 38.69 & 13.01 & & \\
\hline
\end{tabular}

expressed-awareness and expectations about nuclear electrical power technology and nuclear waste in the UAE.

\subsubsection{Nuclear Waste Awareness Across the Seven Emirates}

The between and within emirates relative frequency distributions of UAE youth's nuclear waste awareness are summarized in figure (4). With regards to the between emirates distribution, it can be noted from the blue bars that among the UAE youth that report having never heard of nuclear electrical power technology and nuclear waste, the greatest majority live in Dubai (34.61\%), followed by Abu Dhabi (25\%), then Ras Al Kaimah (10.98\%), Sharjah (8.43\%), Ajman (8.33\%), Fujairah (8.04\%), and finally Umm Al Quwain (4.61\%). Among the youth that report having heard of nuclear electrical power technology and nuclear waste but unable to explain it as shown by the orange bars, the majority also live in Dubai (45.01\%), followed by Abu Dhabi (23.34\%), then Sharjah ( 7.84\%), Ras Al Kaimah (7.32\%), then Ajman and Fujairah (6.89\%), and finally Umm Al Quwain (2.71\%). Furthermore, among those that report knowing about the technology and able to provide general explanations, as shown by the gray bars, the majority live in Dubai (50.61\%), followed by Abu Dhabi (23.85\%), then Sharjah ( 7.37\%), Ajman (5.85\%), Ras Al Kaimah (5.38\%), Fujairah (5.29\%), and finally Umm Al Quwain (1.65\%). Moreover, among those that report being familiar with the technology and able to provide detail explanations, as shown by the yellow bars, the greatest majority once more come from Dubai (57.29\%), followed by Abu Dhabi (22.83\%), then Sharjah (5.64\%), Ras Al Kaimah (4.7\%), Fujairah (4.5\%), and finally Umm Al Quwain (1.14\%). The within emirate distributions suggest that except for Dubai, where the relative frequency of respondents increases with increasing levels of nuclear waste awareness; for all the other emirates, 
the tendency is reversed.

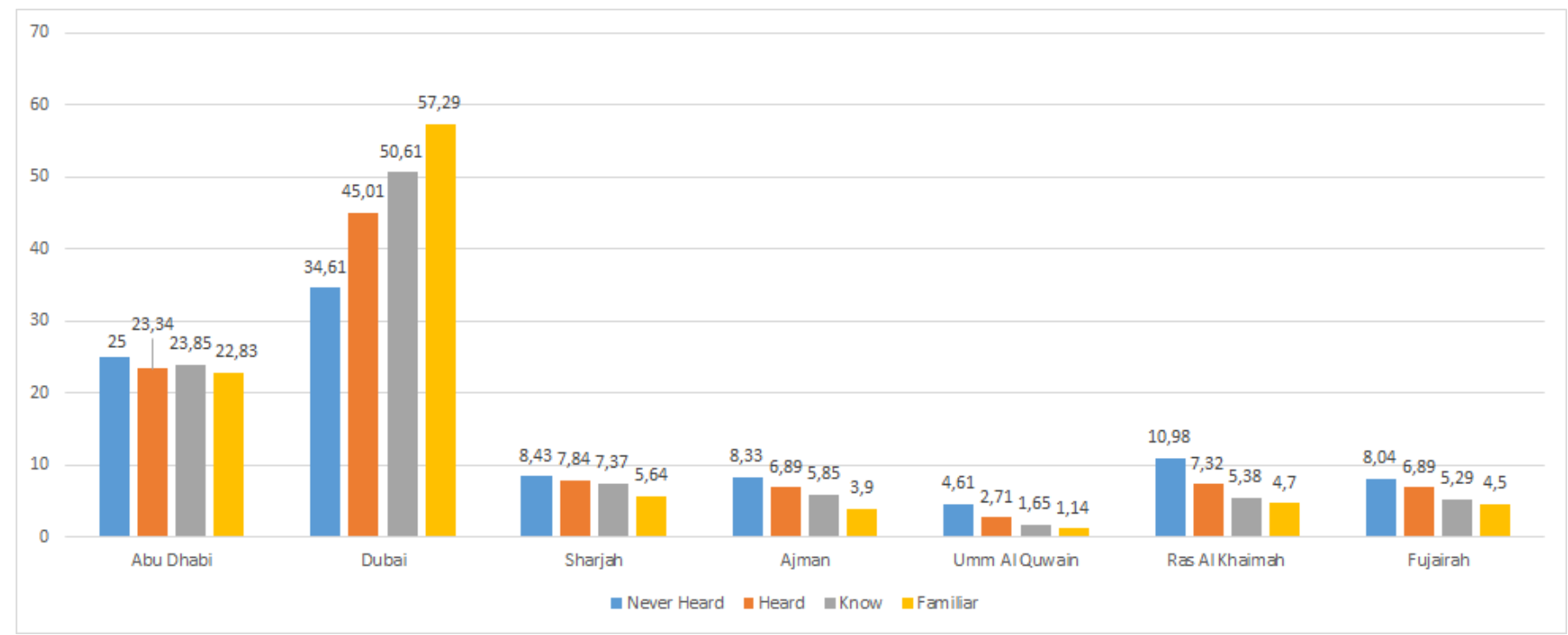

Figure 4: Conditional Percent Frequency of UAE youth's Nuclear Waste Awareness Across the 7 Emirates

\subsubsection{Nuclear Waste Expectations Across the Seven Emirates}

The between and within emirates relative frequency distributions of UAE youth's nuclear waste expectations are summarized in figure (5). With regards to the between emirates distribution, it can be noted from the blue bars that among the UAE youth that reported pessimistic expectations about nuclear electrical power technology and nuclear waste, the greatest majority live in Dubai (40.29\%), followed by Abu Dhabi (25.26\%), then Ras Al Kaimah (9.75\%), Fujairah (7.85\%), Ajman (7.33\%), Sharjah (6.71\%), and finally Umm Al Quwain (2.81\%). Among the youth with stable expectations as shown by the orange bars, the majority also live in Dubai (48\%), followed by Abu Dhabi (23.05\%), then Sharjah ( 8.21\%), Ras Al Kaimah (6.71\%), then Ajman and Fujairah (5.82\%), and finally Umm Al Quwain (2.4\%). Moreover, among the youth with optimistic expectations as shown by the gray bars, the majority live in Dubai (54.27\%), followed by Abu Dhabi (22.85\%), then Sharjah (6.98\%), Ajman (5.38\%), Fujairah (4.68\%), Ras Al Kaimah (4.05\%), and finally Umm Al Quwain (1.79\%). The within emirate distributions of youth expectations about nuclear power technology suggest that except for the emirate of Dubai, where the relative frequency of youth increases with increasing levels of optimism in nuclear power technology, the tendency is reversed for almost all the other emirates. 


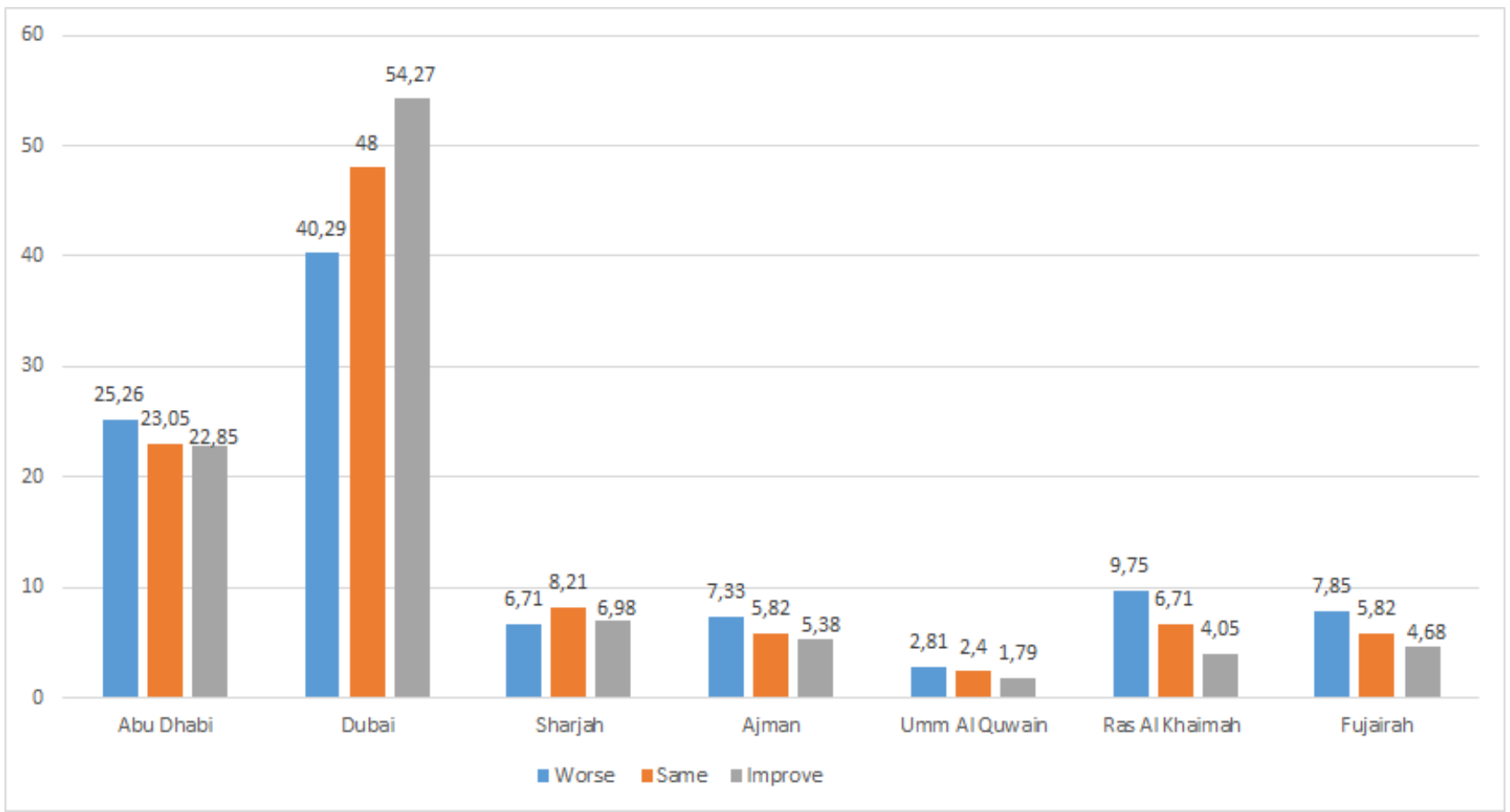

Figure 5: Conditional Percent Frequency of UAE youth's Nuclear Waste Expectations Across the 7 Emirates

\subsection{Econometric Results}

\subsubsection{Interest in Ecosystem Services and Nuclear Waste Awareness and Expectations}

Maximum likelihood estimation (MLE) results for the effects of UAE adolescent's interest in ecosystem services and sustainability on their awareness and expectations about nuclear electrical power technology and nuclear waste are summarized in table (3). Focusing on its effect on awareness in the first column, the statistically significant coefficient value of 0.135 suggests that on average, a level increase in adolescent respondents' interest in ecosystem services and sustainability raises their awareness of nuclear electrical power and nuclear waste by $13.5 \%$. On the opposite, the expectation result in the second column shows a statistically significant coefficient value of 0.024 , suggesting that every level increase in adolescent respondents' interest in ecosystem services and sustainability reduces by $2.4 \%$ their expectations about nuclear electrical power technology and nuclear waste. Together, these two results indicate that interest in ecosystem services and sustainability is a significant determinant of youth awareness and expectations about nuclear electrical power technology and nuclear waste in the UAE. However, although increased interest in ecosystem services and sustainability creates more awareness about the use of nuclear electrical power technology within the UAE youth population, it conjointly leads to less optimism (more pessimism) about the technology. 


\subsubsection{Control variables and Nuclear Waste Awareness in the UAE}

The effects of the control variables on nuclear electrical power technology and nuclear waste awareness are summarized in the first column of table (3). Focusing first on the affective control variables, we note that every level increase in UAE youth's interest in science as a means for disease prevention leads to a $6.2 \%$ increase in their awareness about nuclear electrical power technology and nuclear waste. Similarly, every standard deviation increase in youth's normalized index of science enjoyment raises by $15.9 \%$ their awareness of nuclear electrical power technology and nuclear waste.

The estimated effects for the socio-economic control variables indicate that although age and grade level do not seem to significantly affect youth nuclear technology awareness, factors such as gender, immigration status, economic, social, and cultural status do. In fact, it can be noted that compared to females, young males show $8.7 \%$ more awareness about nuclear electrical power technology and nuclear waste. Similarly, compared to natives of the UAE, first and second generation expatriates are respectively $21.6 \%$ and $39.6 \%$ more aware about nuclear electrical power technology and nuclear waste. Furthermore, the results indicate that every standard deviation increase in youth's index of economic, social, and cultural status, leads to $13.6 \%$ greater awareness about nuclear electrical power technology and nuclear waste in the UAE.

As shown in table (3), sources of information/knowledge also appear to significantly affect youth awareness about nuclear electrical power technology and nuclear waste in the UAE. In fact, every level increase in youth frequency of ecological website visits raises their awareness by $2.9 \%$. On the opposite, a level increase in their frequencies of news blogs visits, broad science book reading, and web browsing on broad science, appear to respectively reduce by $4.9 \%, 5.1 \%$ and $4.6 \%$ UAE youth's awareness about nuclear electrical power technology and nuclear waste.

The regional control dummies at the bottom of the first column in table (3), highlight significant heterogeneity in UAE youth awareness about nuclear electrical power technology and nuclear waste across the 7 emirates. Indeed, compared to their youth counterparts from Abu Dhabi, it can be noted that at the exception of Dubai youth that show $9.3 \%$ more awareness, youth from Sharjah, Ajman, Umm Al Quwain, Ras Al Kaimah, and Fujairah, show respectively 10\%, 11.3\%, 37.9\%, $22 \%$ and $12.4 \%$ less awareness about nuclear electrical power technology and nuclear waste in the UAE.

\subsubsection{Control variables and Nuclear Waste Expectations in the UAE}

The effects of the control variables on UAE youth's expectations about nuclear electrical power technology and nuclear waste are summarized in the second column of table (3). Turning first our attention to the affective control variables, we note that youth's interest in science as a means for disease prevention has no significant impact on their awareness about nuclear electrical power technology and nuclear waste in the UAE. However, every standard deviation increase in youth's normalized index of science enjoyment raises by $2.3 \%$ their level of optimism towards nuclear 
electrical power technology and nuclear waste.

The estimated effects for the socio-economic control variables indicate that factors such as age, gender, grade level, immigration status, economic, social, and cultural status significantly affect youth optimism towards nuclear electrical power technology use in the UAE. In fact, it can be noted that every year increase in age reduces youth level of optimism by $10 \%$. Similarly compared to females, young males show $5.2 \%$ less optimism towards nuclear electrical power technology and nuclear waste. Conversely, the results indicate that every standard deviation increase in UAE youth's index of economic, social, and cultural status, leads to $10 \%$ more optimism towards nuclear electrical power technology and nuclear waste. Moreover, compared to natives of the UAE, first and second generation expatriates are respectively $26.1 \%$ and $39.3 \%$ more optimistic about nuclear electrical power technology and nuclear waste. Unlike the case of youth's awareness, grade level seems to significantly matter in youth's expectations about nuclear power technology and nuclear waste. Indeed, compared to youth in grade seven, those in grades 8, 10, 11, and 12 show respectively $34.7 \%, 28.7 \%, 39.1 \%$, and $33.1 \%$ more optimism towards nuclear electrical power technology use in the UAE.

Furthermore, as shown in the second column of table (3), sources of information/knowledge are also significant determinants of youth expectations about nuclear electrical power technology and nuclear waste in the UAE. In fact, every level increase in youth frequency of ecological website visits raises their optimism level by $9.6 \%$. Similarly, every level increase in UAE youth's frequencies of books reading and web browsing on broad science, appear to raise by respectively $3.6 \%$ and $2.4 \%$ their level optimism towards nuclear electrical power technology and nuclear waste.

The regional control dummies at the bottom of the second column in table (3), also highlight significant heterogeneity in UAE youth's expectations about nuclear electrical power technology and nuclear waste across the 7 emirates. Indeed it can be noted that at the exception of the youth in Ajman and Umm Al Quwain, youth from all four remaining emirates (Dubai, Sharjah, Ras Al Kaimah, and Fujairah) show significantly different levels of optimism compared to their youth counterparts from Abu Dhabi. Indeed while youth from Dubai and Sharjah show respectively 9.3\% and 5.2\% more optimism than their youth counterparts from Abu Dhabi, those from Ras Al Kaimah, and Fujairah show respectively $22.7 \%$ and $11.3 \%$ less optimism towards nuclear electrical power technology and nuclear waste, compared to their youth counterparts from Abu Dhabi. Finally the estimated effects of youth' awareness on their expectations about nuclear electrical power technology and nuclear waste in the UAE, as captured by $\gamma$ in the equation system (1) suggests that controlling for all the other relevant factors (including interest in ecosystem services and sustainability), youth awareness about nuclear technology does not significantly determine how optimistic their are about nuclear technology in the UAE. 


\section{Conclusion and Policy Implications}

This study has relied on the UAE extract from the cross-national data sample on the environmental affection and cognition of adolescent students (Niankara, 2019), along with seemingly unrelated bivariate weighted ordered probit modeling to look at how interest in ecosystem services and sustainability affects nuclear electrical power technology, and nuclear waste awareness and optimism in the UAE youth population. This study was a follow up and complement to Niankara and Zoungrana (2018), which took a global perspective in analyzing the impact of students' interest in the biosphere on their awareness and optimism about the environmental issues of air pollution, water shortage and greenhouse gas emission in 50 countries worldwide. Because the UAE is set to start operations of its first nuclear electrical power plant end of 2019 beginning 2020 (Langton, 2018), this study aimed at providing a clear picture of the UAE adolescent population's awareness and optimism about nuclear technology, so as to contribute in guiding the UAE established nuclear energy program implementation organization, the Emirates Nuclear Energy Corporation (ENEC), in its planning for a sustainable development of nuclear electrical power technology in the country.

Several authors have indeed documented in other countries, the importance of public acceptance of nuclear power technology for its successful development as cleaner alternative and part of a nation's energy mix (Yoshida, 2015; Ramana, 2018; Fan, 2018; Wang et al., 2019). In the case of the UAE, we found that increased interest in ecosystem services and sustainability among present day adolescents leads to more awareness of, while conjointly reducing optimism towards the use of nuclear electrical power technology in the country. In contrast with the USA where Craig and Sayers (2019) reported awareness of local clean energy initiatives, risk perceptions, environmental messaging, and environmental orientation to influence young millennial support for federal clean energy policy and taxes as mediated through local clean energy support, in the present study accounting for all other factors including interest in ecosystem services and sustainability, UAE youth's awareness about nuclear electrical power technology and nuclear waste appeared to not significantly influence their expectations about the evolution of this technology for the next 20 years.

Overall, and in line with the recent systematic review of qualitative and mixed methods research on psychological aspects of living with nuclear energy and technology (Edwards et al., 2019) that pointed out the need for further qualitative research in the area, the present study using seemingly unrelated bivariate weighted ordered probit modeling Niankara and Zoungrana (2018) found significant heterogeneity in youth awareness and expectations about nuclear electrical power technology and nuclear waste across the seven emirates. The youth in Abu Dhabi and Dubai appeared relatively more aware and optimistic compared to those from the other emirates. These results suggest that future campaigns by ENEC to improve public awareness and acceptance of nuclear technology in the UAE should not only target more residents from the other emirates, but also appeal to their biospheric interests in ecosystem services, while clearly emphasizing the 
benefits of nuclear power for energy security and economic growth, in addition to its climate change mitigation capabilities.

Although the topic of energy security, as well as many other policy issues, need to be thought about by the next generation, it is just such issues that the younger generation does not appear eager to tackle face on. Therefore to further raise awareness and optimism about nuclear power technology in the UAE's youth population, ENEC could also draw upon the experience offered by the All Japan Educational Debate Association(Yoshida, 2015, pp. 291), which provides a first hand example of how debate, with its game-like, competitive element can motivate youth to engage with serious issues including that of nuclear technology and nuclear waste management. Such debates could be organized periodically among schools within each emirate, with emirate level champions invited for inter-emirate level debates at a national debating championship.

\section{Disclosure of Funding}

This research did not receive any specific grant from funding agencies in the public, commercial, or not-for-profit sectors.

\section{Declaration of interest}

None 


\section{References}

Ahearne, John F (2011), 'Prospects for nuclear energy', Energy Economics 33(4), 572-580.

AlFarra, Hasan Jamil and Bassam Abu-Hijleh (2012), 'The potential role of nuclear energy in mitigating co2 emissions in the united arab emirates', Energy Policy 42, 272-285.

Arikawa, Hiroshi, Yang Cao and Shigeru Matsumoto (2014), 'Attitudes toward nuclear power and energy-saving behavior among japanese households', Energy Research 65 Social Science 2, 12-20.

Barron, Robert W and Mary C Hill (2019), 'A wedge or a weight? critically examining nuclear power's viability as a low carbon energy source from an intergenerational perspective', Energy Research \& Social Science 50, 7-17.

Budnitz, Robert J, H-Holger Rogner and Adnan Shihab-Eldin (2018), 'Expansion of nuclear power technology to new countries-smrs, safety culture issues, and the need for an improved international safety regime', Energy Policy 119, 535-544.

Chien, Herlin (2014), 'Crisis and essence of choice: explaining post-fukushima nuclear energy policy making', Risk, Hazards $\&$ Crisis in Public Policy 5(4), 385-404.

Coccia, Mario (2014), 'Driving forces of technological change: the relation between population growth and technological innovation: analysis of the optimal interaction across countries', Technological Forecasting and Social Change 82, 52-65.

Cottrell, M Patrick (2017), 'Confronting the nuclear paradox', Energy Research Ef Social Science $24,6-11$.

Craig, Christopher A and Elizabeth L Petrun Sayers (2019), 'Building clean energy support with young millennials in the united states', The Electricity Journal 32(1), 18-24.

Edwards, Michael W, Robert D Schweitzer, Jane Shakespeare-Finch, Aidan Byrne and Keely Gordon-King (2019), 'Living with nuclear energy: A systematic review of the psychological consequences of nuclear power', Energy Research $\&$ Social Science 47, 1-15.

Eveloy, Valerie and Tesfaldet Gebreegziabher (2019), 'Excess electricity and power-to-gas storage potential in the future renewable-based power generation sector in the united arab emirates', Energy 166, 426-450.

Fan, Mei-Fang (2018), 'Risk discourses and governance of high-level radioactive waste storage in taiwan', Journal of Environmental Planning and Management pp. 1-15. 
Gattie, David K, Joshua L Darnell and Joshua NK Massey (2018), 'The role of us nuclear power in the 21st century', The Electricity Journal 31(10), 1-5.

Harris, Jill, Maureen Hassall, Grace Muriuki, Celestien Warnaar-Notschaele, Eric McFarland and Peta Ashworth (2018), 'The demographics of nuclear power: Comparing nuclear experts', scientists' and non-science professionals' views of risks, benefits and values', Energy research \&3 social science 46, 29-39.

Ho, Shirley S, Alisius D Leong, Jiemin Looi and Agnes SF Chuah (2019), 'Online, offline, or wordof-mouth? complementary media usage patterns and credibility perceptions of nuclear energy information in southeast asia', Energy Research 8 Social Science 48, 46-56.

Hvidt, Martin (2017), 'Nuclear power in the united arab emirates: A case for public debate?', Videncenter Om Det Moderne Mellemøsten .

Jackman, S (2000), 'Models for ordered outcomes [pdf document]', Retrieved on 25 March 2018 from Lecture notes Online Web site: http://www. stanford. edu/class/polisci203/ordered. pdf.

Jacobson, Mark Z (2009), 'Review of solutions to global warming, air pollution, and energy security', Energy \& Environmental Science 2(2), 148-173.

Juaidi, Adel, Francisco G Montoya, Jose A Gázquez and Francisco Manzano-Agugliaro (2016), 'An overview of energy balance compared to sustainable energy in united arab emirates', Renewable and Sustainable Energy Reviews 55, 1195-1209.

Khondaker, AN, Md Arif Hasan, Syed Masiur Rahman, Karim Malik, Md Shafiullah and Musah A Muhyedeen (2016), 'Greenhouse gas emissions from energy sector in the united arab emirates-an overview', Renewable and Sustainable Energy Reviews 59, 1317-1325.

Ki-moon, Ban (2016), 'Sustainability-engaging future generations now', The Lancet 387(10036), 2356-2358.

Knapp, Vladimir and Dubravko Pevec (2018), 'Promises and limitations of nuclear fission energy in combating climate change', Energy Policy 120, 94-99.

Langton, James (2018), 'Uae's first nuclear power plant delayed until late 2019 or 2020', The National, 27 May. Retrieved December 2018, from. https://www.thenational.ae/uae/uae-s-firstnuclear-power-plant-delayed-until-late-2019-or-2020-1.734445.

Lenzen, Manfred (2008), 'Life cycle energy and greenhouse gas emissions of nuclear energy: A review', Energy conversion and management 49(8), 2178-2199. 
Lim, Xiao Y, Dominic CY Foo and Raymond R Tan (2018), 'Pinch analysis for the planning of power generation sector in the united arab emirates: A climate-energy-water nexus study', Journal of Cleaner Production 180, 11-19.

McKelvey, Richard D and William Zavoina (1975), 'A statistical model for the analysis of ordinal level dependent variables', Journal of mathematical sociology 4(1), 103-120.

Nagraj, Aarti (2018), 'Uae nuclear power plant over 90\% complete', Golf Business, 16 December. Retrieved December 2018, at. https://gulfbusiness.com/uae-nuclear-power-plant-90-complete/.

Niankara, Ibrahim (2018), 'Scientific Media Dieting and Students Awareness and Expectations about the Environmental Issues of Deforestation and Species Extinction in the Middle East and North America: An Integrated cross Cultural Ecologic-Economic Analysis', Preprints, pp. 1-33, Retrieved on 17 May 2018 from (doi: 10.20944/preprints201804.0267.v1).

Niankara, Ibrahim (2019), 'Cross-national data sample on the environmental affection and cognition of adolescent students of varying interests in ecosystem services and sustainability', Data in Brief 22(February), 312-318.

Niankara, Ibrahim and Didier T Zoungrana (2018), 'Interest in the biosphere and students environmental awareness and optimism: A global perspective', Global Ecology and Conservation 16, e00489, https://doi.org/10.1016/j.gecco.2018.e00489.

OECD (2016), Programme for International Student Assessment (PISA) 2015 Database: Stduent Questionnaire data file, Organization for Economic Co-operation and Development, Paris, France. Retrieved on 30 March 2018 from.

URL: $h t t p: / / w w w . o e c d . o r g / p i s a / d a t a / 2015 d a t a b a s e /$

OECD (2017), PISA 2015 Technical Report: Chapter 04 - Sample design, Organization for Economic Co-operation and Development, Paris, France. Retrieved on 30 March 2018 from.

URL: http://www.oecd.org/pisa/sitedocument/PISA-2015-technical-report-final.pdf

Ozcan, Burcu and Ayse Ari (2017), 'Nuclear energy-economic growth nexus in oecd countries: a panel data analysis', International Journal of Economic Perspectives 11(1), 138-154.

Park, Ki-Chan and Françoise Chevalier (2010), 'The winning strategy of the late-comer: how korea was awarded the uae nuclear power contract', International Review of Business Research Papers 6(2), 221-238.

Pioro, I and R Duffey (2019), Current status of electricity generation in the world and future of nuclear power industry, in 'Managing Global Warming', Elsevier, pp. 67-114. 
Portugal-Pereira, J, P Ferreira, J Cunha, A Szklo, R Schaeffer and M Araújo (2018), 'Better late than never, but never late is better: Risk assessment of nuclear power construction projects', Energy Policy 120, 158-166.

R Core Team (2015), R: A Language and Environment for Statistical Computing, R Foundation for Statistical Computing, Vienna, Austria.

URL: https://www.R-project.org/

Ramana, MV (2018), 'Technical and social problems of nuclear waste', Wiley Interdisciplinary Reviews: Energy and Environment p. e289.

Reuters (2018), 'Uae nuclear body says not ready to licence company to operate plant', Golf Business, 21 November. Retrieved December 2018, from. https://gulfbusiness.com/uae-nuclearbody-says-not-ready-licence-company-operate-plant/.

Richter, Jennifer (2017), 'Energopolitics and nuclear waste: Containing the threat of radioactivity', Energy research \&o social science $\mathbf{3 0 , 6 1 - 7 0 . ~}$

Saif, Y and A Almansoori (2016), 'A capacity expansion planning model for integrated water desalination and power supply chain problem', Energy conversion and management 122, 462476.

Sajaia, Zurab (2008), 'Maximum likelihood estimation of a bivariate ordered probit model: implementation and monte carlo simulations', The Stata Journal 4(2), 1-18.

Sarrias, Mauricio (2016), 'Discrete choice models with random parameters in R: The Rchoice package', Journal of Statistical Software 74(10), 1-31.

Schmidt, Karl-Heinz and Beatriz Jurado (2018), 'Review on the progress in nuclear fission-experimental methods and theoretical descriptions', Reports on Progress in Physics 81(10), 106301.

Sgouridis, Sgouris, Ayu Abdullah, Steve Griffiths, Deger Saygin, Nicholas Wagner, Dolf Gielen, Hannes Reinisch and Dane McQueen (2016), 'Re-mapping the uae's energy transition: An economy-wide assessment of renewable energy options and their policy implications', Renewable and Sustainable Energy Reviews 55, 1166-1180.

Sgouridis, Sgouris, Steve Griffiths, Scott Kennedy, Arslan Khalid and Natalia Zurita (2013), 'A sustainable energy transition strategy for the united arab emirates: Evaluation of options using an integrated energy model', Energy Strategy Reviews 2(1), 8-18. 
Shahbaz, Muhammad, Rashid Sbia, Helmi Hamdi and Ilhan Ozturk (2014), 'Economic growth, electricity consumption, urbanization and environmental degradation relationship in united arab emirates', Ecological Indicators 45, 622-631.

Sim, Li-Chen (2012), 'Re-branding abu dhabi: From oil giant to energy titan', Place Branding and Public Diplomacy 8(1), 83-98.

Sornette, Didier, Wolfgang Kröger and Spencer Wheatley (2019), Potentials and vision for the future of nuclear energy, in 'New Ways and Needs for Exploiting Nuclear Energy', Springer, pp. 257-276.

Sovacool, Benjamin K and Scott Victor Valentine (2012), The national politics of nuclear power: economics, security, and governance, Routledge.

Stefanelli, Annalisa, Roman Seidl and Michael Siegrist (2017), 'The discursive politics of nuclear waste: Rethinking participatory approaches and public perceptions over nuclear waste storage repositories in switzerland', Energy research \& social science $\mathbf{3 4}, \mathbf{7 2 - 8 1 .}$

Tammi, Ilpo, Kaisa Mustajärvi and Jussi Rasinmäki (2017), 'Integrating spatial valuation of ecosystem services into regional planning and development', Ecosystem Services 26, 329-344.

Treyer, Karin and Christian Bauer (2016), 'The environmental footprint of uae's electricity sector: combining life cycle assessment and scenario modeling', Renewable and Sustainable Energy Reviews 55, 1234-1247.

Turconi, Roberto, Alessio Boldrin and Thomas Astrup (2013), 'Life cycle assessment (lca) of electricity generation technologies: Overview, comparability and limitations', Renewable and sustainable energy reviews 28, 555-565.

Uddin, Kamal (2019), 'Nuclear energy, environment and public safety: North-south politics', Strategic Planning for Energy and the Environment 38(4), 31-41.

Van Ness, Peter and Mel Gurtov (2017), Learning from Fukushima: Nuclear Power in East Asia, ANU Press.

Wang, Shanyong, Jing Wang, Shoufu Lin and Jun Li (2019), 'Public perceptions and acceptance of nuclear energy in china: The role of public knowledge, perceived benefit, perceived risk and public engagement', Energy Policy 126, 352-360.

Wheatley, Spencer, Benjamin K Sovacool and Didier Sornette (2016), 'Reassessing the safety of nuclear power', Energy Research \&6 Social Science 15, 96-100. 
World Nuclear Association (2018), 'Nuclear power in the united arab emirates', Country Profiles, Retrieved on December 2018, from. http://www.world-nuclear.org/information-library/countryprofiles/countries-t-z/united-arab-emirates.aspx.

World Nuclear News (2017), 'Uae poll shows growing support for nuclear', World Nuclear News, 15 April. Retrieved December 2018, from. http://www.world-nuclear-news.org/NP-UAE-pollshows-growing-support-for-nuclear-05041702.html.

Yoshida, Akemi (2015), Considering the geological disposal program of high-level radioactive waste through classroom debate, in 'Nuclear Back-end and Transmutation Technology for Waste Disposal', Springer, Tokyo, pp. 289-299.

Zahlan, Rosemarie Said (2016), The origins of the United Arab Emirates: A political and social history of the Trucial States, Routledge. 
Table 2: Descriptive Statistics of the Explanatory Variables used in the Regression Model. $(\mathrm{N}=6919)$

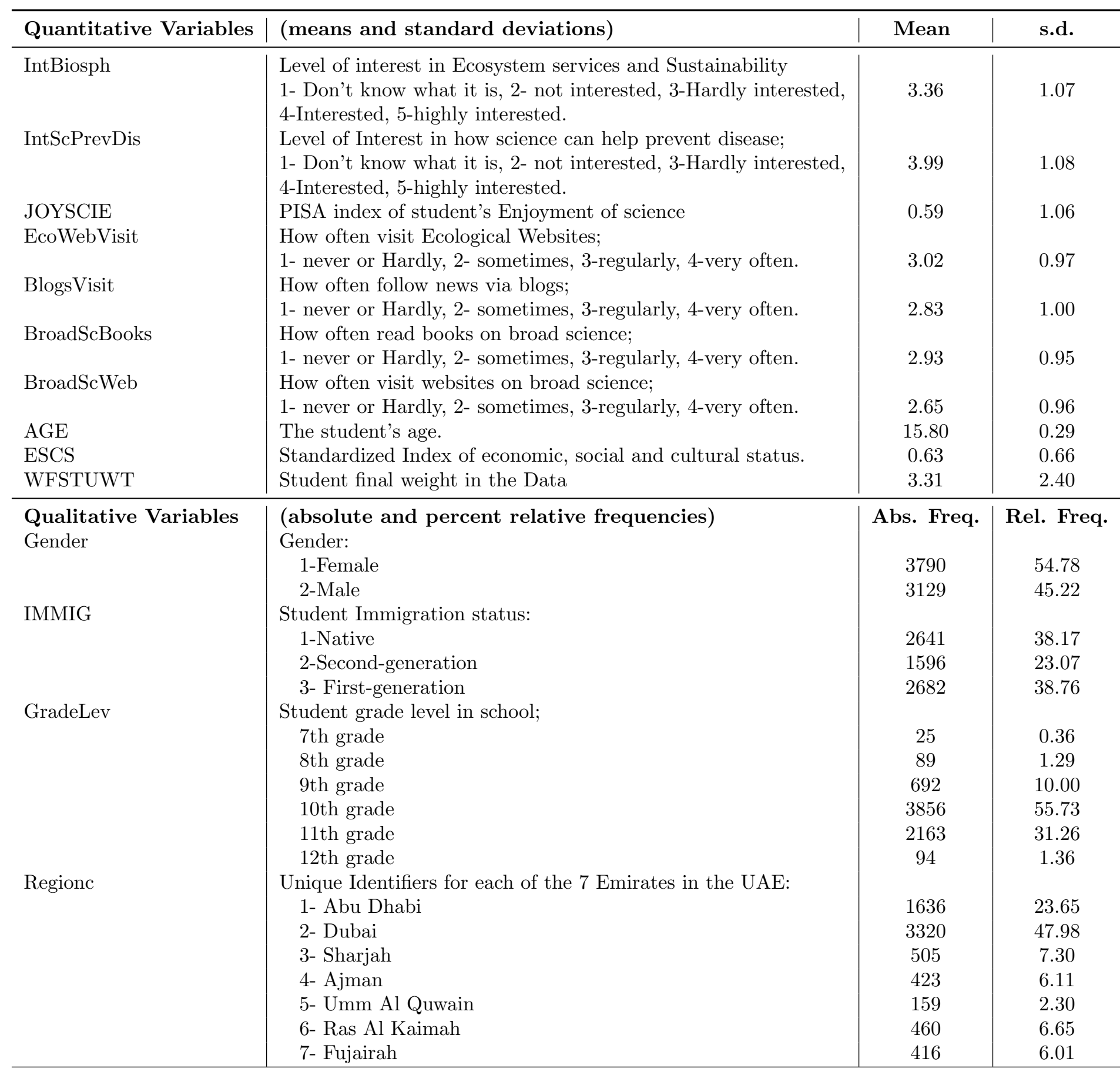

Source: Authors' construction using the UAE extract of the published data (Niankara, 2019). 
Table 3: MLE Results for Adolescents Nuclear Waste Awareness and Expectations in the UAE

\begin{tabular}{|c|c|c|c|c|}
\hline $\begin{array}{l}N \\
6919\end{array}$ & $\begin{array}{c}\text { Awareness } \\
\text { Coef. }\end{array}$ & \multicolumn{3}{|c|}{ Expectations } \\
\hline Cutoff 2 & $\mu_{2}=1.032^{* * *}$ & $(0.011)$ & $\delta_{2}=0.875^{* * *}$ & $(0.009)$ \\
\hline Cutoff 3 & $\mu_{3}=2.042^{* * *}$ & $(0.014)$ & & \\
\hline (Intercept) & $0.584^{* * *}$ & $(0.456)$ & $1.194^{*}$ & $(0.480)$ \\
\hline IntBiosph & $0.135^{* * *}$ & $(0.008)$ & $-0.024^{* *}$ & $(0.008)$ \\
\hline \multicolumn{5}{|l|}{ Affective controls } \\
\hline IntScPrevDis & $0.062^{* * *}$ & $(0.007)$ & -0.002 & $(0.008)$ \\
\hline JOYSCIE & $0.159^{* * *}$ & $(0.008)$ & $0.023^{* *}$ & $(0.008)$ \\
\hline \multicolumn{5}{|c|}{ Demographic \& economic controls } \\
\hline AGE & 0.009 & $(0.027)$ & $-0.100^{* * *}$ & $(0.029)$ \\
\hline GenderM & $0.087^{* * *}$ & $(0.015)$ & $-0.052^{* * *}$ & $(0.016)$ \\
\hline ESCS & $0.136^{* * *}$ & $(0.011)$ & $0.100^{* * *}$ & $(0.011)$ \\
\hline (IMMIG) 2 & $0.216^{* * *}$ & $(0.019)$ & $0.261^{* * *}$ & $(0.020)$ \\
\hline (IMMIG) 3 & $0.396^{* * *}$ & $(0.018)$ & $0.393^{* * *}$ & $(0.019)$ \\
\hline GradeLev8 & -0.186 & $(0.150)$ & $0.347^{*}$ & $(0.158)$ \\
\hline GradeLev9 & -0.195 & $(0.138)$ & 0.277 & $(0.146)$ \\
\hline GradeLev10 & -0.137 & $(0.137)$ & $0.287^{*}$ & $(0.144)$ \\
\hline GradeLev11 & 0.072 & $(0.137)$ & $0.391^{* *}$ & $(0.145)$ \\
\hline GradeLev12 & 0.155 & $(0.149)$ & $0.331^{*}$ & $(0.157)$ \\
\hline \multicolumn{5}{|l|}{ Knowledge controls } \\
\hline EcoWebVisit & $0.029^{* *}$ & $(0.011)$ & $0.096^{* * *}$ & $(0.011)$ \\
\hline BlogsVisit & $-0.049^{* * *}$ & $(0.010)$ & 0.016 & $(0.011)$ \\
\hline BroadScBooks & $-0.051^{* * *}$ & $(0.011)$ & $0.036^{* *}$ & $(0.011)$ \\
\hline BroadScWeb & $-0.046^{* * *}$ & $(0.011)$ & $0.024^{*}$ & $(0.011)$ \\
\hline \multicolumn{5}{|c|}{ Regional control dummies } \\
\hline Dubai & $0.093^{* * *}$ & $(0.018)$ & $0.093^{* * *}$ & $(0.019)$ \\
\hline Sharjah & $-0.100^{* * *}$ & $(0.021)$ & $0.052^{*}$ & $(0.022)$ \\
\hline Ajman & $-0.113^{* *}$ & $(0.035)$ & 0.014 & $(0.037)$ \\
\hline Umm Al Quwain & $-0.379^{* * *}$ & $(0.084)$ & -0.075 & $(0.087)$ \\
\hline Ras Al Khaimah & $-0.220^{* * *}$ & $(0.032)$ & $-0.227^{* * *}$ & $(0.034)$ \\
\hline Fujairah & $-0.124^{* *}$ & $(0.041)$ & $-0.113^{* *}$ & $(0.043)$ \\
\hline Awareness (SEANW) & & & -0.005 & $(0.008)$ \\
\hline Log-likelihood & \multicolumn{2}{|c|}{-28698.1} & \multicolumn{2}{|c|}{-24408.3} \\
\hline $\mathrm{BIC}$ & \multicolumn{2}{|c|}{57626.1} & \multicolumn{2}{|c|}{49046.4} \\
\hline $\mathrm{AIC}$ & \multicolumn{2}{|c|}{57448.3} & \multicolumn{2}{|c|}{48868.5} \\
\hline
\end{tabular}

${ }^{* * *} p<0.001,{ }^{* *} p<0.01,{ }^{*} p<0.05$ 